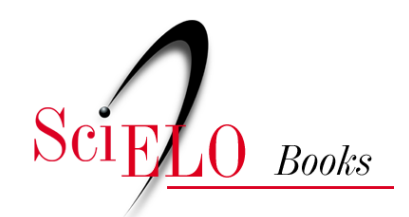

\title{
Aproximando os campos gênero e Hip-hop
}

\author{
Rebeca Sobral Freire
}

\section{SciELO Books / SciELO Livros / SciELO Libros}

FREIRE, R.S. Aproximando os campos: gênero e Hip-hop. In: Hip-hop feminista? Convenções de gênero e feminismos no movimento Hip-hop soteropolitano [online]. Salvador: EDUFBA/NEIM, 2018. Bahianas collection, n. 20, pp. 25-41. ISBN: 978-85-232-1862-1.

https://doi.org/10.7476/9788523218621.0003.

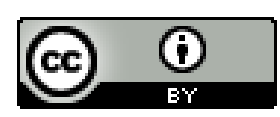

All the contents of this work, except where otherwise noted, is licensed under a Creative Commons Attribution $\underline{4.0 \text { International license. }}$

Todo o conteúdo deste trabalho, exceto quando houver ressalva, é publicado sob a licença Creative Commons Atribição 4.0.

Todo el contenido de esta obra, excepto donde se indique lo contrario, está bajo licencia de la licencia Creative Commons Reconocimento 4.0. 


\section{APROXIMANDO OS CAMPOS: gênero e Hip-hop}

A experiência de um estudo sobre as mulheres no hip-hop, desde o início, foi considerada um desafio a ser enfrentado, respectivamente, nos campos da Ciência Política e dos Estudos Interdisciplinares de Gênero e Feminismos. Ao fundamentar essa proposta na teoria feminista permitiu-se romper com uma concepção restrita do que seria "político"3 e adotar uma visão ampla, que abarca o diálogo entre a política e a cultura. Assim, ocorreu o mapeamento do diálogo entre perspectivas diversas de conhecimento que compartilharam o interesse sobre a relação gênero e hip-hop.

Originado nos Estados Unidos, ${ }^{4}$ na década de 1970, o Hip-hop caracteriza-se como um movimento político e cultural constituído sob a influência de dois importantes movimentos ocorridos no mesmo país. O primeiro, o Movimento dos Direitos Civis, ocorrido

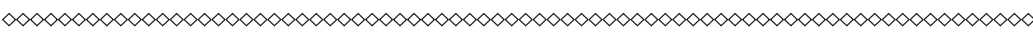

3 Inicialmente vinculado a uma interpretação institucionalizada, mais ligada ao campo do formal da "política", a exemplo de partidos, eleições, cargos representativos, mandatos, políticas públicas etc.

4 É usado o termo "estadunidense" para o que for oriundo dos Estados Unidos, em oposição ao termo "americano", que mantém a perspectiva colonizadora em relação ao continente; sendo usado "americano" para todos os países do continente. 
nas décadas anteriores, liderados por Rose Parks e Martin Luther King Jr. e, o segundo, inspirado pelo movimento Black Power, referendado por Angela Davis e o grupo Panteras negras.

Ambos os movimentos precursores do hip-hop compartilhavam, respectivamente, pautas de combate às desigualdades sociais, mais especificamente direcionadas para as questões de cunho racial. De acordo com Patrícia Hill Collins (2006), a ascensão do hip-hop representa o período pós-movimentos por direitos civis e é marcada pelo fim do movimento Black Power, surgindo como uma alternativa à cegueira sobre o mito do fim do racismo no país ${ }^{5}$ e da promoção do "sonho americano" de iguais oportunidades para todas as pessoas; ainda, a "guetização" (ghettoization) dos pobres e da classe trabalhadora negra e jovem estadunidense.

A mídia americana criou e transmitiu comercialmente o Hip-hop como uma espécie de "cultura negra americana" (black american culture), vinculado à pobreza, às drogas, à violência e à hipersexualização dos corpos negros, especialmente das mulheres negras. Collins (2006) explica que essa propaganda publicizou o estilo fashion da negritude a partir dos elementos do hip-hop, transformando-o em uma indústria de milhões de dólares. Assim, o Hip-hop, em seus vários aspectos, tornou-se alvo de interesse de estudos das Ciências Sociais. A autora aponta que a geração jovem, formada por adolescentes e recentes jovens adultos nascidos após as conquistas da Era dos movimentos por direitos civis (integração racial) e dos processos de crises econômicas nos Estados Unidos, independente de classe social, gênero, raça ou etnia, ou orientação sexual, compartilha esse período como uma etapa de politização da vida social.

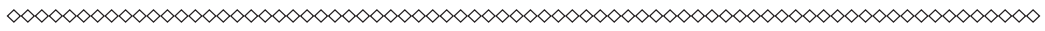

5 Sobretudo pelo lado institucional que marca o fim das leis de segregação racial nos Estados Unidos que apartavam a população branca e negra.

6 Entendo "gueto" como referência a um espaço restrito à convivência entre determinado grupo étnico e classe pobre, que passa a determinar estilo e condições de vida diante da exclusão social. 
Vale ressaltar que as conquistas alcançadas pelos movimentos por direitos civis dos Estados Unidos ecoaram pelo mundo e influenciaram movimentos de luta por cidadania de outros países. Como esta juventude do "Black Power para o Hip Hop" (COLLINS, 2006) teria voz para questionar os problemas que enfrentam em seu cotidiano, a ponto de inspirar e compartilhar experiências de desigualdades e estratégias de superação das mesmas, estando em lugares tão distantes?

O Hip-hop, como um movimento de juventude, se expandiu pelo mundo a partir de seus quatro elementos artísticos: 1) Break, ${ }^{7}$ é a dança de rua; 2) Grafite, ${ }^{8}$ é a expressão das artes plásticas nos muros da cidade; 3) Rap, ${ }^{9}$ é a música, sendo o $D J^{10}$ o responsável pelo beat - a batida. Apenas quando unidas essas expressões constituem o hip-hop, ao promoverem em uma articulação entre cultura e política. Há que se considerar um "quinto elemento" que permeia seus elementos clássicos: a politização que motiva a participação juvenil individual e coletiva em questões relevantes ao seu cotidiano e suas identidades, muitas vezes identificadas pelos jovens do movimento por "militância".

Na década de 1980, o Hip-hop chega as principais capitais brasileiras, São Paulo e Rio de Janeiro, inserido num contexto de problemas sociais que acometem a população periférica. Sua cultura e

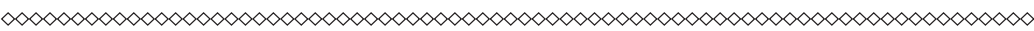

7 A mulher que dança break, em seus vários estilos, é chamada de $b$-girl e o homem de $b$-boy.

8 A mulher que grafita, em seus vários estilos, é chamada de grafiteira e o homem de grafiteiro, pois trabalham basicamente os sprays para grafitar, desenhar utilizando a técnica do spray. Uma questão importante é a distinção entre a grafitag’em e a pichação, sendo a primeira considerada uma arte urbana que se inicia nos muros da cidade e depois adentra inclusive em galerias de arte, expondo questões do cotidiano urbano e questões vigentes da sociedade, enquanto a pichação é reconhecida como uma poluição visual e violação urbana com o intuito apenas de depreciar os espaços das cidades.

9 A mulher ou homem que cantam rap em seus vários estilos compartilham o nome de rapper ou Mc (Mestre de cerimônia).

10 A mulher que toca na pick-up (equipamentos eletrônicos que tocam diversos discos de vinil de diferentes estilos musicais, criando samples - recortes de batidas musicais diversas - também em seus vários estilos, atualmente também se utilizando de computadores e programas de áudio para edição destas novas batidas) é chamada de Djeia e o homem de DJ. 
estética de afirmação da identidade negra agitaram os bailes black, iniciados pelo funk, festas dançantes que priorizam estilos musicais a partir de bandas e artistas negros nacionais e internacionais, a exemplo de James Brown e Jorge Ben Jor. Evento comum nas periferias, esses bailes estimularam um cenário de danças, vestimentas e variados penteados para os cabelos crespos, através dos quais se destacava o chamado estilo black power, desafiando a imposição de um modelo de beleza vinculado à "branquitude".

Nesse período, na cidade de Salvador, acontecia o baile Black Bahia, no bairro periférico Periperi, do qual participavam grupos de dança de funk, a exemplo dos grupos Cobra funk (apenas meninos) e Cobra funk girls (meninas a partir de dez anos), que apresentavam as primeiras expressões do hip-hop com dança e música. Em 1996, as primeiras expressões do hip-hop se uniram para a formação de seu primeiro grupo, a Posse Ori, quando se concretiza a formação do hip-hop como um movimento social.

De acordo com Aldenora Lima (2006, p. 13), as posses podem ser entendidas como “[...] um núcleo de atuação e reflexão do movimento Hip-hop, local onde ocorrem reuniões semanais e são discutidos os projetos futuros e divulgados eventos e festas". Priscila Matsunaga (2008) atualiza um novo termo para esses grupos, também chamados de crew, tendo uma conotação específica para grupos de dança e/ou de grafite. Ambas autoras concordam que, a partir de suas manifestações artísticas, mulheres e homens jovens do hip- hop passam a interpretar politicamente a sua própria cidadania.

Além dos trabalhos artísticos realizados em torno dos elementos do hip-hop, as posses promovem atividades nas comunidades, que assumem diversos formatos, como palestras em escolas e faculdades (WELLER, 2000) e participação em mesas de debate em seminários, congressos e aberturas de encontros de diferentes temáticas sociais, em especial com foco racial e de 
juventude. Foi a partir das "posses” que o hip-hop soteropolitano congregou jovens de um mesmo bairro ou região, os quais desenvolviam os elementos que caracterizam o movimento e atuavam politicamente em torno de demandas de sua comunidade e de problemas que afligiam seu cotidiano.

A partir da inserção nas posses e grupos de hip-hop (a exemplo das bandas de rap), muitos jovens puderam sair de seus bairros de origem localizados na periferia - em sua maioria distantes do centro histórico e tradicional da cidade - para circularem por outros bairros, incluindo o centro. ${ }^{11}$ Essa oportunidade lhes permitiu não apenas a criação de novas rotas, de deslocamentos, mas também adentrar em espaços políticos e históricos da cidade, conhecer pessoas e participar de outras atividades culturais e políticas, que abordavam temas diversos.

Hoje o hip-hop pode ser encontrado nas grandes capitais de todo o mundo e também nas cidades do interior de diferentes estados e países. As cidades, em especial os grandes centros urbanos, são os maiores cenários de propagação do hip-hop e seus elementos, considerando sua evidência prioritariamente em contextos de desenvolvimento, migrações e, sobretudo, intensas desigualdades sociais. (BILL, 2005)

Na Bahia, estado nordestino que reúne um dos maiores contingentes de negros, marcado por grandes disparidades no que se refere à distribuição de renda, esse movimento destaca o aspecto racial como extremamente relevante para o reconhecimento de sua identidade pessoal e de grupo. Além disso, a crescente afirmação da presença das mulheres, como constatada nesta

11 Muitas vezes, esses jovens frequentavam lugares e circuitos urbanos a que seus pais, mães e familiares ainda não tinham ido, por restringirem sua circulação à região dos bairros onde moram, ou mesmo dirigindo-se ao centro apenas esporadicamente ou raramente quando vinculados a algum trabalho, necessidades médicas ou burocráticas, não exatamente conhecendo e frequentando lugares de lazer gratuitos como praças, teatros e o próprio Centro Histórico do Pelourinho (Diário de Campo, Reunião "Curso de formação de b-girls", abril 2008). 
pesquisa, destaca aspectos relevantes da configuração do recente movimento Hip-hop soteropolitano.

Para tanto, é dada a prioridade, neste momento, à contextualização do contato com o universo da pesquisa. Embora já fosse difundido socialmente o elemento musical do hip-hop, o rap, nos anos 2000 o hip-hop se destaca fortemente como movimento social em Salvador. O interesse de investigação sobre o tema se deu a partir de uma rica experiência junto ao hip-hop no III Encontro de Gênero e Hip-Hop, no ano de 2005, em Lauro de Freitas. (FREIRE, 2010) Essa atividade destacou o potencial do hip-hop como tema e objeto de estudo, sobretudo pela crescente participação das mulheres que afirmavam sua pauta na agenda do movimento.

No geral, aquele cenário propiciava o levantamento de uma série de problemáticas envolvendo a preocupação com a cidadania da juventude negra baiana, e, em especial, da periferia. Essa preocupação estava diretamente relacionada não apenas à luta por direitos, mas também em objetivar prioritariamente naquele espaço a discussão sobre as relações (de gênero) entre homens e mulheres, homens e homens, e mulheres e mulheres e sobre o contexto de reprodução da hegemonia masculina dentro do próprio movimento e suas implicações no cotidiano e na própria militância de seus integrantes.

O que chamou atenção foi o fato de terem sido as próprias mulheres as produtoras daquele espaço de discussão e que priorizaram, na programação do evento, a participação dos homens em seu segundo dia. Essa é uma experiência inédita ou, no mínimo, inovadora, diante das experiências de outros grupos e segmentos políticos mistos de movimentos sociais vigentes na época. Outros dois aspectos relevantes são a autoidentificação deste segmento como jovem e seu envolvimento com questões em torno do feminismo. 
A partir dessa experiência, foi perceptível a rentabilidade analítica que o estudo do movimento Hip-hop, de característica jovem, feminista e negra, traria para diferentes campos de estudo, simultaneamente. Já que, de um lado, questiona a hegemonia do sujeito homem de análise dos estudos da política e, de outro, desafia a predominância das mulheres adultas como foco dos estudos feministas e de gênero. (FREIRE, 2010) Além disso, essa experiência inclui os elementos dos campos de estudo sobre identidade, vinculados às relações étnico-raciais e de idade/geração, ambas desprivilegiadas nos estudos de gênero e da política.

No que se refere à participação das mulheres jovens, com o foco sob o aspecto geracional, assumem um caráter distinto em relação às mulheres adultas, havendo uma lacuna em relação à sua participação em manifestações político-culturais. (WELLER, 2005) No caso da participação das mulheres e de outros sujeitos subalternizados, é fundamental seu resgate histórico devido à necessidade de se compreender a importância dos registros da realidade histórica no passado, sua repercussão no presente e suas possibilidades para o futuro.

Nesse caso, a ausência e pouca visibilidade das mulheres também são constatadas nos estudos sobre hip-hop, nos quais se encontra uma predominância masculina em sua representação (MARTINS, 2004; MIRANDA, 2006; MORAES NETO, 2006; OLIVEIRA, 2007), e/ou quando a participação das mulheres não é compreendida a partir de uma perspectiva feminista de gênero. No entanto, no Brasil tem se expandido, nos últimos anos, uma produção científica interessada nas experiências da juventude, vinculadas ao movimento Hip-hop em contato com gênero e feminismo, estabelecidas entre mulheres e homens, e mulheres e mulheres, no espaço do movimento e em seus elementos culturais e artísticos. 
A maioria desses estudos estão voltados para apenas um único elemento do hip-hop como objeto de pesquisa, o rap. Para tanto, serão apresentados alguns dos trabalhos que exemplificam essa exclusividade de olhares para este elemento, muitas vezes também chamado pelo próprio nome "hip-hop" pelo público geral ou devido ao senso comum em torno desse estilo musical. ${ }^{12}$

É o que mostra o trabalho sobre as performances das integrantes de bandas femininas de distintos estilos musicais da região de Florianópolis (SC), de Rodrigo Gomes (2008). Entre cinco bandas pesquisadas, uma delas é identificada com o estilo hip-hop, chamada "Declínio do Sistema”, o que evidencia a participação das mulheres no elemento musical do hip-hop. De acordo com o autor, a partir da performance das rappers:

Percebemos que as mulheres, em especial mulheres negras, estão encontrando um significativo espaço para fomentar discussões sobre as causas femininas, provendo através das letras das canções a conscientização das mulheres sobre os temas como aborto, cuidado com o corpo, uso de anticoncepcionais. Este também é um lócus para a divulgação dos seus direitos civis, como, por exemplo, licença maternidade, aposentadoria para donas de casa e domésticas, denúncia à violência contra mulheres, etc. (GOMES, 2008, p. 144)

Além disso, Gomes (2008) salienta a necessidade de mais estudos sobre a crescente participação das mulheres no meio musical, como produtoras e consumidoras dessa arte em desenvolvimento no país. No campo da arte, a música representa um espaço privilegiado para analisar a sociedade, seja através das personalidades atuantes e suas expressões artísticas diversas, sejam musicais, teatrais, dança ou artes plásticas. Entretanto,

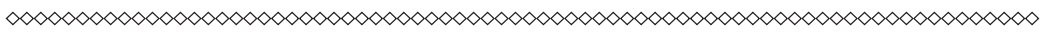

12 De natureza autoral em sua maioria, as letras e músicas de rap são escritas e interpretadas pelos próprios compositores e compositoras rappers. Para compor o repertório da banda, pode-se encontrar grupos de rap que possuem composições em grupo/coletivas ou que compartilham uma letra de autoria de apenas um de seus integrantes. 
o autor não se propõe a avaliar a relação das bandas com grupos do movimento de mulheres ou mesmo com posses do hip-hop.

Priscila Matsunaga (2008) também aborda as representações sociais das mulheres no movimento Hip-hop através do rap. Ela analisa 32 letras de rap de homens e mulheres, sendo produções originadas de Piracicaba e São Paulo, e constata a existência de três papéis femininos: mãe/namorada, negra batalhadora e objeto vulgar. Nesse contexto, é possível perceber o posicionamento de algumas rappers, identificadas como feministas pela autora, devido à resistência a se converterem ao discurso dominante de hierarquização entre homens (acima) e mulheres (abaixo), que orienta comportamentos preestabelecidos por sexo também no hip-hop, além da busca por ampliação dos espaços de debate sobre suas demandas políticas. Entretanto, a autora não avança em questionar posições relacionadas a uma identidade feminina ou feminista pelas hip hoppers.

"Há feministas no Hip-Hop, mesmo diante do cenário de predominância masculina?”. (SILVA, 1995) Essa é uma pergunta relevante e compartilhada de interesse neste livro. Segundo "O rap das meninas", de Maria Aparecida da Silva, as mulheres do hip-hop estavam presentes nos mais importantes encontros feministas, nacionais e internacionais, inclusive na Conferência de Beijing, ${ }^{13}$ e tiveram relevante papel de articulação e fortalecimento do movimento de mulheres e feminista brasileiro e latino-americano.

A autora justifica que "[...] estas garotas tem a manha, a artimanha, a malemolência de um samba miudinho para se movimentarem em espaços predominantemente masculinos" (SILVA, 1995, p. 516), e também para adentrar em espaços considerados exclusivos às mulheres adultas. Afirma, ainda, que assumidas

$\infty<\infty<\infty<\infty<\infty<\infty<\infty<\infty<\infty<\infty<\infty<\infty<\infty<\infty<\infty<\infty<\infty<\infty<\infty<\infty<\infty<\infty<\infty<\infty<\infty<\infty<\infty<\infty<\infty<\infty<\infty$

13 A Conferência de Beijing, como ficou conhecida a IV Conferência Mundial Sobre as Mulheres, que aconteceu na capital da China, Beijing, no ano de 1995, reuniu delegações governamentais e organizações não governamentais de diversos países para discutirem questões relacionadas às mulheres. 
como feministas ou não, sem rótulos, as rappers paulistanas que se autoidentificaram como negras mostraram consciência das desigualdades de gênero, raça e geração a serem superadas. Estas afirmaram utilizar o rap como um desabafo para suas questões e como um meio para serem ouvidas. Contudo, a pesquisa de Silva aponta que não há uma preocupação das interlocutoras em se afirmarem feministas ou não, não chegando a aprofundar o entendimento acerca das concepções sobre o feminismo pelas mesmas e seus argumentos em defesa, oposição ou mesmo adesão a esta identidade política.

Todas as pesquisas consultadas apontaram experiências de discriminação das mulheres em relação à sua expressão artística do rap e às suas performances no palco do hip-hop. São vivências marcadas, muitas vezes, pela busca de impor limites às ações das jovens não apenas nos palcos, mas também relacionadas ao controle de seus corpos, desde a roupa que usam nas atividades do movimento, no seu comportamento sexual em relacionamentos dentro do grupo, além das próprias restrições vinculadas às oportunidades de trabalho no campo da música rap. (SILVA, 1995; MATSUNAGA, 2008; GOMES, 2008) Juntos, esses trabalhos contribuíram para demarcar a imagem das mulheres no Hip-hop, e, em especial, nas letras e performances do rap.

São compartilhadas pelas pesquisas conclusões acerca dos aspectos de manutenção de uma visão discriminatória em relação às mulheres diante da reprodução de uma hegemonia do modelo masculino como referência de "sujeito" legítimo àquele espaço, sob a afirmação da identidade negra e da periferia através da "cultura política” do Hip-hop. É o que mostra no Brasil o desenvolvimento de uma produção científica recente interessada na participação política das mulheres jovens.

Este "pensamento jovem feminista brasileiro" responde por um campo ainda em construção no país, portanto, uma categoria 
ainda não estabilizada, mas que se constitui pelos critérios de uma postura que se afirma feminista e jovem (sem exatamente uma faixa etária preestabelecida), estando preocupada em problematizar experiências de militância da juventude, em especial feminina, a partir de um novo olhar da teoria feminista sobre a pluralidade de expressões (diálogo entre categorias) do feminismo como movimento social.

No Brasil, pode-se citar o exemplo de uma publicação especial, uma coletânea que reúne em sua primeira versão trabalhos que se reconhecem jovens e feministas, intitulada por "Jovens feministas presentes” (2009). São trabalhos de jovens pesquisadoras preocupadas em ampliar o campo de atuação da teoria feminista, que trazem novas referências e experiências de atuação, organização e intervenção das mulheres jovens nos espaços de poder, tais como no movimento social, nos canais de participação e nas políticas públicas.

O artigo "Jovens no feminismo e no Hip Hop na busca por reconhecimento" busca analisar os desafios e alternativas encontradas pelas jovens mulheres inseridas no movimento Feminista e no movimento Hip-hop, dois espaços de militância bastante distintos. (ZANETTI; SOUZA, 2009) Julia Zanetti e Patrícia Souza expõem os conflitos geracionais e avanços conquistados no movimento Feminista em relação à juventude, além da contextualização do fenômeno Hip-hop no Brasil e no mundo, expondo a pouca participação das mulheres neste cenário.

Essas autoras concluem que, a partir dos anos 1990, com a atuação das mulheres do hip-hop e seu atrelamento com o campo do feminismo enquanto articulações e pautas, “o movimento feminista foi obrigado a reconhecer um novo grupo demandando espaço e visibilidade para sua própria forma de perceber e expressar suas questões”. (ZANETTI; SOUZA, 2009, p. 101) Da mesma forma, o hip-hop tem sido obrigado a reconhecer a participação do 
movimento de mulheres e feministas hip hoppers como parte dele. Esse é o primeiro trabalho que enfoca a relação direta do movimento de mulheres do hip-hop com o movimento Feminista, priorizando contextualizar seus conflitos e desafios. No entanto, elas não aprofundam questões em torno dos significados desse feminismo para o próprio movimento Hip-hop, que o produz de uma forma diferenciada em ação e pensamento de um feminismo apenas jovem, e, especialmente, em um movimento misto.

Já no artigo "Hip Hop Mulher: experiências de organização", Atiely Santos e Fernanda Sunega (2009) problematizam o conceito de participação política das mulheres hip hoppers para além do âmbito formal e partidário ao darem visibilidade às manifestações e intervenções nos espaços públicos das cidades ou centros urbanos. Além disso, a autonomia das organizações de mulheres é apresentada nas diversas articulações entre outras organizações, grupos, movimentos e instituições feministas.

As autoras destacam a relação desse movimento com o uso de novas tecnologias. Esse uso pode ser marcado em dois momentos. Num primeiro momento, já desde seu início nos anos 1970, nos Estados Unidos, e em seguida no decorrer de sua expansão pelo mundo nos anos posteriores, esse envolvimento esteve implícito com o uso e desenvolvimento dos toca-discos, microsystem, pick-ups, radiolas, fitas k-7, discos de vinil e outros. Alguns desses materiais ainda seguem os hip hoppers, em especial DJs em seu trabalho atual.

Num segundo momento, caracterizado por seu aspecto relativamente recente, há também a utilidade das ferramentas tecnológicas que são em primeiro plano, o acesso e aprendizagem para lidar com o computador e a internet, em segundo plano, pesquisas e produção de espaços virtuais, como sites e blogs, e participação em articulação em listas de discussão, $e$-mails, comunidades virtuais, dentre outros, no intuito de fortalecimento de contatos e 
divulgação de atividades das redes gerais e específicas, a exemplo de redes feministas virtuais do hip-hop. Tem se falado inclusive de militância virtual, muito utilizada por homens e mulheres hip hoppers para estabelecerem contatos e organizarem ações de pequeno, médio e grande porte pelo movimento.

Essa alternativa de participar, mesmo que virtualmente em muitos momentos, tem permitido e ampliado as possibilidades de trocas entre indivíduos e grupos de diferentes locais, como divulgação de atividades. A internet tem sido uma brecha para inserção do hip-hop, em especial para as mulheres jovens, muitas vezes sobrecarregadas por dupla e tripla jornada de trabalho ao cuidar de casa, crianças, estudo e trabalho que as ligam ao espaço doméstico,o que as diferencia em relação ao homem jovem, que não atende, em sua maioria, a essas funções vinculadas ao lar e à família, tendo, portanto, mais acesso ao espaço público.

No universo hip-hop brasileiro, o aspecto étnico-racial tem uma dimensão identitária relevante diante da maioria das jovens militantes do movimento Hip-hop que se autoidentificam como negras. Essa participação pode ser entendida como parte do rol da atuação das jovens feministas negras. Os desafios enfrentados pelas jovens negras para acessar espaços como os dos movimentos sociais se convertem em uma dupla barreira diante das discriminações raciais e de gênero (SILVA, 1995; CARVALHO; QUINTILIANO, 2009), além de fazerem referência aos contextos de classe e território nos quais a maior parte delas está inserida as periferias urbanas.

As experiências de mulheres em determinados grupos e segmentos do hip-hop soteropolitano servem de base para a criação de um movimento de mulheres interno ao Movimento. Questiona-se se essa organização de mulheres se constitui como parte do movimento Feminista, uma vez que compartilham algumas das suas lutas, tais como a autonomia feminina, a legalização do aborto, 
o empoderamento das mulheres, o combate à violência contra a mulher, dentre outros. Esses grupos e indivíduos teriam uma preocupação ou mesmo uma defesa de uma identidade politicamente feminista, basicamente feminina, ou nenhuma das duas posições? Também é importante observar que, dentre suas bandeiras, o movimento soteropolitano e de mulheres do Hip-hop também agrega as questões geracional e étnico-racial.

Tendo em vista tais questionamentos sobre as especificidades do movimento de mulheres do/no hip-hop, a fim de investigar as convenções de gênero e atitudes políticas engendradas nesse movimento soteropolitano, do ponto de vista das militantes, toma-se como hipótese de análise que esse movimento constitui-se a partir da combinação particular de três matrizes ou gramáticas políticas, a saber: movimento Feminista, movimento Negro e movimento de Juventude.

O movimento Feminista, muitas vezes, se apresenta como distinto do movimento de mulheres ou do movimento de mulheres negras, por se opor ao caráter classista e branco das primeiras gerações do feminismo. Esses movimentos têm bandeiras centradas no combate do sexismo e do racismo embasadas pelo combate à violência contra as mulheres. Outros aspectos importantes são as questões das mulheres negras discriminadas no mercado de trabalho, no que tange aos salários e postos de trabalho, muitas vezes negados a elas; há também a discussão e regularização de assuntos como trabalho doméstico, atendimentos nos serviços públicos de saúde, e outras questões.

Com relação ao movimento Negro, destacam-se a preocupação com formulações de leis e implementação de políticas de todos os setores, podendo citar em especial as de combate ao racismo, como leis de educação que interferem nos conteúdos de disciplinas do ensino fundamental e médio, na inclusão da história e cultura africana e afro-brasileira e nas políticas de ações afirmativas nas 
universidades públicas (estaduais e federais), a exemplo das políticas de cotas e programas de permanência estudantil. Dentre outros, há quatro temas vigentes nessa gramática política que devem ser mencionados aqui: a área de saúde da população negra, como o exemplo do caso da anemia falciforme; o direito à prática das religiões de matrizes africanas; o combate à intolerância religiosa; e a forma particular sobre como o racismo aflige as mulheres negras.

Já o movimento de Juventude é marcado pela luta por inclusão no mercado de trabalho sem os critérios de boa aparência mediante a apresentação de foto e, mais específico do Hip-hop, a profissionalização de seus elementos como trabalhos de arte-educação. O quesito violência se destaca contra homens e mulheres. Os homens jovens são vítimas da violência urbana devido ao extermínio da juventude negra, e as mulheres jovens vitimadas diante da prática do aborto inseguro. Ambos os temas relevantes elencados pelo Fórum Nacional de Juventude Negra no I Encontro Nacional de Juventude Negra (Enjune), realizado em junho de 2007, na cidade de Lauro de Freitas, Região Metropolitana de Salvador. (CARVALHO; QUINTILIANO, 2009)

Estas três gramáticas ou matrizes políticas compartilham o incentivo à afirmação de identidades e ao aprendizado para lidar com as diferenças. São três gramáticas que se mantêm em diálogo e constante interação na configuração desse cenário hip-hop soteropolitano.

Por conseguinte, a partir de inquietações acerca da atuação das jovens no movimento social Hip-hop, a investigação se dá em torno de como se configuram "as convenções de gênero e feminismos" no movimento Hip-hop em Salvador em relação à existência de um hip-hop feminista, jovem, negro, soteropolitano. Para tanto, como prioridade está a atenção à perspectiva das mulheres inseridas nesse movimento, sobretudo o interesse 
em compreender quais são suas concepções acerca do feminismo (ou o feminino), e investigar se há e quais são suas contribuições para as experiências destas mulheres diante de um contexto que dialoga com uma cultura política local vigente.

$\mathrm{Na}$ construção desta pesquisa, alguns questionamentos se desdobram a partir da questão central: existe um hip-hop jovem, feminista, soteropolitano? Se sim, como se constitui? Quais as suas concepções, referências e práticas em torno do modelo de feminilidade e de masculinidade que se expressam em suas convenções de gênero? Há feministas no hip-hop? O que elas entendem por feminismo? Há diferentes feminismos? Quais são suas distinções? Que tipo de feminismo estas constroem? Esses feminismos são capazes de apontar estratégias de superação das diferenças entre homens e mulheres e explicar as convenções de gênero acerca dos modelos de masculinidade e de feminilidade? Os homens podem ser feministas? Essas são algumas das questões que motivaram e orientaram esta pesquisa.

Ocorreu a adoção de algumas convenções na escrita deste livro de forma a identificar determinadas particularidades textuais. Para tanto, é utilizado itálico para identificar as falas das interlocutoras no corpo do texto e também para palavras estrangeiras. Utilizo letra tamanho dez para distinguir os fragmentos de notas do diário de campo, e aspas para destacar conceitos e expressões em uso. Vale destacar que, a fim de auxiliar a leitura, foi criado um glossário com o vocabulário do universo hip-hop.

No segundo capítulo, “O Hip-hop não para!”, são apresentados os aspectos teórico-metodológicos que orientaram a pesquisa, juntamente com as técnicas de investigação utilizadas para a sua realização.

O terceiro capítulo, "Hip-hop: coisa de menina? Convenções de gênero no movimento Hip-hop soteropolitano”, tem por objetivo identificar as convenções de gênero que embasam os modelos 
de feminilidade e de masculinidade, forjadas a partir de experiências vivenciadas no âmbito do movimento hip-hop soteropolitano, na perspectiva das mulheres militantes.

No quarto capítulo, "Hip-hop: espaço de contestação das convenções de gênero?”, são levantadas algumas interpretações sobre esse movimento como um espaço de contestação das convenções de gênero. As hip hoppers descobrem nesse movimento, mesmo que majoritariamente masculino, uma "brecha" para as mulheres e sua pauta política, interessadas em utilizar o aspecto de protesto do movimento como um instrumento capaz de contestar as convenções de gênero.

O quinto capítulo, "Agora os meninos precisam saber que coisa de menina também é coisa de menino! Hip-hop feminista?”, apresenta as considerações analíticas sobre as concepções de feminismos e discursos das hip hoppers em torno de um hip-hop feminista, enquanto apresento as conclusões da pesquisa. 